\title{
Selection and characterization of non-ideal ionic liquids mixtures to be used in $\mathrm{CO}_{2}$ capture
}

\author{
Mónia A.R. Martins a, b, c, Gyanendra Sharma ${ }^{\text {d }}$, Simão P. Pinho ${ }^{\text {b, c }}$, Ramesh L. Gardas ${ }^{\text {d, }}$ \\ João A.P. Coutinho ${ }^{\text {a }}$, Pedro J. Carvalho ${ }^{\text {a, * }}$ \\ a CICECO - Aveiro Institute of Materials, Department of Chemistry, University of Aveiro, 3810-193, Aveiro, Portugal \\ ${ }^{\mathrm{b}}$ Associate Laboratory LSRE-LCM, Department of Chemical and Biological Technology, Polytechnic Institute of Bragança, 5300-253, Bragança, Portugal \\ ${ }^{\mathrm{C}}$ CIMO - Mountain Research Center, Polytechnic Institute of Bragança, 5300-253, Bragança, Portugal \\ d Department of Chemistry, Indian Institute of Technology Madras, Chennai, 600 036, India
}

\section{A R T I C L E I N F O}

\section{Article history:}

Received 19 February 2020

Received in revised form

20 April 2020

Accepted 22 April 2020

Available online 6 May 2020

\section{Keywords:}

ILs mixtures

COSMO-RS

Density

Excess molar volumes

Viscosity

\begin{abstract}
A B S T R A C T
Due to the costs involved, the capture of $\mathrm{CO}_{2}$ in post-combustion is not currently seen as economically viable. Aiming at changing the perception of post-combustion $\mathrm{CO}_{2}$ from a costly and non-profitable process to a valuable commodity and fostering the development of the next-generation of technologies, novel solvents and their mixtures have been investigated. In this work, mixtures of non-volatile ionic liquids were screened by COSMO-RS aiming to find mixtures with positive excess volumes that could present an increased $\mathrm{CO}_{2}$ capture by physical sorption. The most promising mixtures identified by COSMO-RS, $\left[\mathrm{C}_{4} \mathrm{C}_{1} \mathrm{im}\right][\mathrm{DMP}]$ or $\left[\mathrm{C}_{4} \mathrm{C}_{1} \mathrm{im}\right]\left[\mathrm{NTf}_{2}\right]+$ carboxylate-based protic ILs were characterized through the measurement of their thermophysical properties, namely density and viscosity. Both properties were measured for pure ILs and their binary mixtures at different temperatures and compositions. The temperature dependence of density of pure ILs was described using the Gardas and Coutinho model while viscosity was accurately described using the Vogel-Tammann-Fulcher equation. The Redlich-Kister equation was used to predict the excess molar volumes and the non-ideality of the mixtures' viscosity was assessed using the Grunberg and Nissan mixing law. The excess molar volumes for mixtures containing $\left[\mathrm{C}_{4} \mathrm{C}_{1} \mathrm{im}\right][\mathrm{DMP}]$ show large positive values all over the range of compositions and temperatures, making them good candidates for $\mathrm{CO}_{2}$ capture. To the best of our knowledge, the excess molar volumes obtained in this work were the highest reported so far. COSMO-RS was able to correctly predict the trend of the experimental excess molar volumes for these mixtures. Regarding viscosity, mixtures of $\left[C_{4} C_{1} i m\right]$ [DMP] with the carboxylate-based protic ILs led to the desired viscosity decrease compared to the pure aprotic IL, and large deviations from ideality were observed. The mixing of ILs is thus an efficient way to fine-tune the properties, in this case decreasing the viscosity while increasing the sorption capacity.
\end{abstract}

() 2020 Elsevier B.V. All rights reserved.

\section{Introduction}

Human dependency and consumption on fossil fuels is a major source of greenhouse gases (GHGs). Among the anthropogenic GHGs, carbon dioxide $\left(\mathrm{CO}_{2}\right)$ stands as one with the most important contribution with over $84 \%$ energy-related emissions. Its growing atmospheric concentration results from the fossil fuel combustion, particularly power plant emissions [1]. The global economic expansion and the rising energy demand in developing countries

\footnotetext{
* Corresponding author.

E-mail address: quijorge@ua.pt (P.J. Carvalho).
}

anticipates an increase of these emissions in the near future, leading to concerns over permanent climate changes and to the need to implement of climate-related initiatives capable to mitigate the GHGs effects.

Currently, the conventional technology used in industry is based on amine absorption processes that while presenting advantages, like operation stability, high capacity and good reactivity; are also costly and may be environmentally harmful [2]. There is thus a growing interest in developing innovative technologies for an efficient and economic capture of $\mathrm{CO}_{2}$ [3]. Technologies involving adsorption, membrane separation or carbamation stand as promising alternatives for $\mathrm{CO}_{2}$ capture [3-7].

Due to their outstanding properties, ionic liquids (ILs) have been 
studied as alternatives to replace solvents commonly used in physical sorption of $\mathrm{CO}_{2}[3,8,9]$. Their tunability, low vapour pressure, thermal stability and high solvating capacity $[10,11]$ make this class of neoteric solvents suitable for $\mathrm{CO}_{2}$ capture and separation from other streams. However, most ILs present high viscosities limiting their industrial application. The possibility of fine-tuning their properties through their structural manipulation or formulated mixtures, may allow to overcome the current limitations while keeping the solvation potential [9]. Although mixing ILs with different molecular weights and chemical structures can be used to tune the solvent viscosity, it is also known for the negative impact on the sorption capacity. The correct selection of ILs may however overcome this limitation by tuning the Hildebrand solubility parameter, matching the solubility parameter of the ILs mixture with that of the gas of interest, or/and increase the solvent free volume and thus, increasing the gas solubility. In fact, several studies have proposed mixtures of ILs with lower viscosities while enhancing the $\mathrm{CO}_{2}$ solubility and selectivity [12-14]. Nevertheless, the available data is scarce and discrepancies are observed among the authors, which calls for further studies in this field [8]. The first step is to provide a complete thermophysical characterization of ILs mixtures that, albeit of indisputable importance, is still scarce. These data, combined to $\mathrm{CO}_{2}$ solubility measurements, will be of great interest for the development of theoretical tools, like equations of state, correlations, group contribution models, and more importantly for their implementation in process simulators to accurately design and scale-up industrial separation processes.

Density and viscosity, the physical properties investigated in this work, are of great importance in absorption processes. If on the one hand, an increased viscosity can significantly reduce the mass transfer coefficients causing slower diffusion of $\mathrm{CO}_{2}$ to the bulk liquid and leading to larger separation unities [15]; on the other, systems with positive excess volumes are expected to have enhanced physical solubility due to the increase of the solvent free volume and thus, higher solubility.

The large number of possible ionic liquids mixtures to be investigated makes impractical an exhaustive characterization of these systems. Thus, the use of experimental data for the validation of computational tools, like the Conductor-like Screening Model for Real Solvents - COSMO-RS - predictive model [16], is essential so that models can be used for a screening and identification of the ionic liquids, and their mixtures, with the highest potential for a given purpose.

Knowing that the solubility of gases in pure ionic liquids is ruled by physisorption with the gas occupying the free volume within the ILs voids $[8,17,18]$, COSMO-RS was used here as a predictive tool to identify the most promising mixtures of ionic liquids with positive deviations from ideality (i.e. activity coefficients, $\gamma$, greater than one) and thus, expectably, positive excess volumes and consequently enhanced solubility. However, it is important that this increased non-ideality does not promote a complete phase separation, previously reported for specific ionic liquid mixtures [19-21]. However, for ionic liquid mixtures, Omar et al. [22] reported that mixtures presenting excess enthalpies higher than $500 \mathrm{~J} \mathrm{~mol}^{-1}$ usually lead to phase separation. Therefore, in this work the selection of the mixtures was carried using these two constraints: positive deviations from ideality and excess enthalpies lower than $500 \mathrm{~J} \mathrm{~mol}^{-1}$.

Aiming to establish grounds for the development of new and sustainable technologies capable of meeting the global climate change goals and to expand the state of carbon management options, the characterization of mixtures of ILs is here carried out. COSMO-RS is used to make an extensive screening of the ionic liquids and ionic liquids families with the highest potential for the proposed separation. Then the thermophysical characterization of their densities and viscosities is addressed, allowing to understand the behavior/property duality necessary for the development of theoretical models and to build a complete description of the solvent properties.

\section{Experimental}

\subsection{Chemicals}

Six protic ionic liquids based on the $N, N$-diethylethanolammonium $\left([D E E A]^{+}\right)$or $N$-butyl-2-hydroxyethyl ammonium $\left([\mathrm{BHEA}]^{+}\right)$cations combined with the anions Acetate $\left([\text { Ace }]^{-}\right)$, Propanoate $\left(\left[\right.\right.$Prop $\left.^{-}\right)$, Butanoate $\left([\text {But }]^{-}\right)$, Pentanoate ([Pent $\left.]^{-}\right)$or Hexanoate $\left([\mathrm{Hex}]^{-}\right)$and the aprotics 1-butyl-3methylimidazolium dimethylphosphate, $\left(\left[\mathrm{C}_{4} \mathrm{C}_{1} \mathrm{im}\right][\mathrm{DMP}]\right)$ or 1 butyl-3-methylimidazolium bis(trifluoromethanesulfonyl)imide $\left(\left[\mathrm{C}_{4} \mathrm{C}_{1} \mathrm{im}\right]\left[\mathrm{NTf}_{2}\right]\right)$ were used in this work. The ionic liquids name, mass fraction purity, molecular weight, supplier and chemical structure are reported in Table 1 . The water content of the ionic liquids and their mixtures was determined by a Metrohm 831 Karl Fischer coulometer using the analyte Hydranal $\mathbb{R}$-Coulomat AG from Riedel-de Haën.

\subsubsection{Protic ionic liquid synthesis}

The synthesis of the carboxylate-based protic ILs has been detailed in previous publications [23,24]. To reduce the water content and volatile impurities, the ILs were dried and purified under vacuum (1 Pa) at room temperature for at least $48 \mathrm{~h}$. The structures of the obtained compounds were analysed by ${ }^{1} \mathrm{H}$ and ${ }^{13} \mathrm{C}$ NMR - Fig. S1 of supporting information. As can be seen by the ${ }^{1} \mathrm{H}$ NMR spectra, while the protic ILs [DEEA][But], [DEEA][Pent] and [BHEA][Ace] are in the 1:1 (cation:anion) proportion; the remaining are in the 1:2 (cation:anion) proportion due to the formation of an azeotrope during the distillation purification step. As reported by Ribeiro et al. [25], mixtures of organic superbases with carboxylic acids lead to the formation of azeotropic mixtures with an acid/ base proportion different from the initially prepared 1:1. This happens due to the ability of carboxylic acids to form strong hydrogen bonds with the protic ionic liquid ion pair leading to an azeotropic composition rich in acid. A similar behavior was observed by Yoshizawa et al. [26] for $\alpha$-picoline + trifluroacetic acid where the boiling point reaches a maximum at $67 \%$ of acid, corresponding to the formation of the highly stable $\mathrm{H}(\mathrm{TFA})_{2}^{-}$anion. The fact that this was observed only for three, out of six, protic ionic liquids prepared seems to be related with the vapour pressure of the components and the extension of the purification step. Nonetheless, shorter purifications steps would, regardless, lead to cation:anion proportions that converge to the $1: 2$ equilibrium ratio. The change of composition has a direct influence in the properties and applications of the compound and thus was here considered.

\subsection{Methods}

\subsubsection{COSMO-RS}

The Conductor-like Screening Model for Real Solvents is a predictive model for thermophysical properties of fluids and liquid mixtures based on unimolecular quantum calculations. Theoretical details can be found elsewhere [16,27]. Prior to the predictive process, TURBOMOLE 6.1 program package was used to generate the input files of the different molecules [28]. A BP functional B88p86 with a triple- $\xi$ valence polarized basis set (TZVP) and the resolution of identity standard (RI) approximation were used. ILs were described by an equimolar mixture of the lowest energy conformations of the cations and anions that contribute as two different compounds. COSMOtherm was then used to perform the statistical 
Table 1

Name, chemical structure, molecular weight, mass fraction purity and supplier of the investigated compounds.

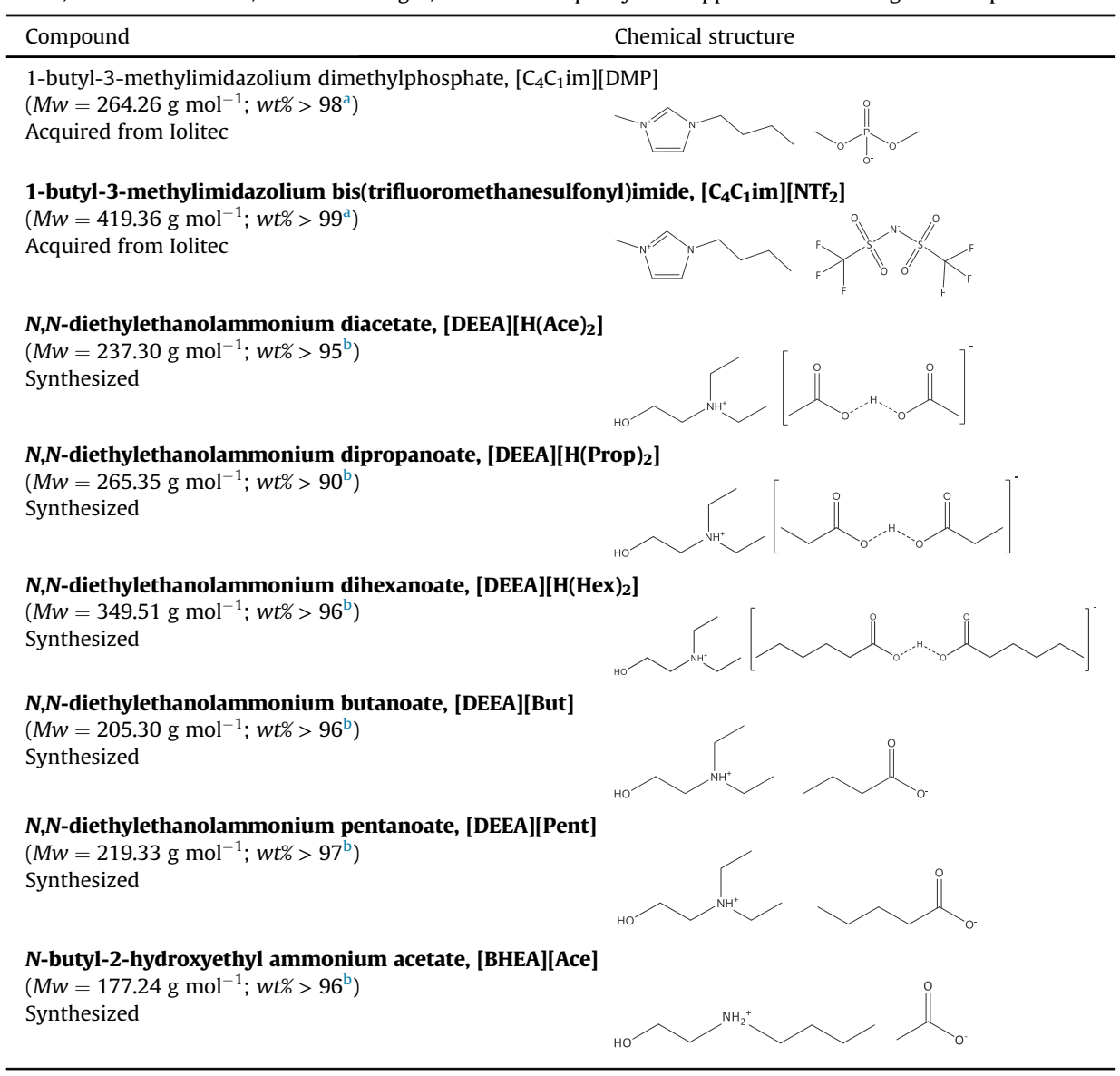

a Declared by the supplier.

b Determined by NMR.

thermodynamics calculations using the BP_TZVP_C30_1701 (COSMOconfX v3.0, COSMOlogic GmbH \& Co KG. Leverkusen, Germany) parameterization.

\subsubsection{Mixtures preparation}

Mixtures were prepared with the dried ILs in a dry-argon glovebox and at room temperature using an analytical balance model ALS 220-4 N from Kern with a reproducibility of $0.2 \mathrm{mg}$. Vials with mixtures were heated at $323.15 \mathrm{~K}$ under stirring for at least $2 \mathrm{~h}$.

\subsubsection{Density and viscosity}

Densities and viscosities were measured using an automated SVM 3000 Anton Paar rotational Stabinger viscometer-densimeter (with a temperature uncertainty of $0.02 \mathrm{~K}$, a dynamic viscosity relative uncertainty of $0.35 \%$ and a density absolute uncertainty of $5 \times 10^{-4} \mathrm{~g} \mathrm{~cm}^{-3}$ ), working at atmospheric pressure. Densities and viscosities measurements were performed once for each sample but repeated with new random samples with similar compositions.

\section{Results and discussion}

\subsection{COSMO-RS screening}

COSMO-RS was initially used to perform a screening of the ionic liquids mixtures with the highest potential for the $\mathrm{CO}_{2}$ absorption. As starting point, the works of Claudio et al. [29], Omar et al. [22] and Moya et al. [30] were taken into account. Claudio et al. [29] used COSMO-RS to estimate the hydrogen-bond basicity of pure ILs and established polarity scales capable of ranking ILs according to their chemical behaviours, while Omar et al. [22] used the same tool to evaluate the mixing behavior of IL-IL systems through the evaluation of the excess enthalpy. The non-ideal behavior of mixtures of ionic liquids was analysed in-depth by Moya et al. [30].

Based on these studies, an initial set of compounds with the following criteria was chosen: ILs formed by the common $\left[\mathrm{C}_{4} \mathrm{C}_{1} \mathrm{im}\right]$ cation and the acetate, dimethylphosphate, bis(trifluoromethanesulfonyl)imide or hexafluorophosphate anions were chosen, due to the significant differences between their hydrogenbonding interaction energies as stated in the work of Claudio et al. [29]; miscible mixtures with an excess enthalpy in the range $[52-500] \mathrm{J} \cdot \mathrm{mol}^{-1}$ were selected based on the article of Omar et al. [22]; and the two ILs mixtures with higher $\mathrm{CO}_{2}$ solvation power identified by Moya et al. [30] $\left(\left[\mathrm{C}_{2} \mathrm{C}_{1}\right.\right.$ im $][\mathrm{DCN}]+\left[\mathrm{C}_{2} \mathrm{C}_{1}\right.$ im $]\left[\mathrm{NTf}_{2}\right]$ and $\left.\left[\mathrm{C}_{2} \mathrm{C}_{1} \mathrm{im}\right]\left[\mathrm{NTf}_{2}\right]+\left[\mathrm{C}_{2} \mathrm{C}_{1} \mathrm{im}\right]\left[\mathrm{EtSO}_{4}\right]\right)$ were included. Fifteen carboxylate-based protic ILs investigated by us before $[23,24,31]$ were also added to the screening pool, due to the reported potential $\mathrm{CO}_{2}$ capture capacity [32,33].

More than 200 mixtures, composed by 9 cations and 12 anions (Table S1), were evaluated. The equimolar binary mixtures excess enthalpies $\left(H^{\mathrm{E}}\right)$ were calculated at $298.15 \mathrm{~K}$ using COSMO-RS Table S2 and Fig. S2 of Supporting Information. The ILs mixtures with activity coefficients greater than 1 , that may lead to positive excess volumes and enhanced gas solubility, were selected for further characterization. Furthermore, Omar et al. [22] reported 
that mixtures with excess enthalpies higher than $500 \mathrm{~J} \mathrm{~mol}^{-1}$ tend to be immiscible and thus, aiming to avoid phase separation, this value was taken as an upper limit for the ILs mixtures selection as well.

Fig. 1 depicts the IL-IL mixtures with positive excess enthalpies lower than $500 \mathrm{~J} \mathrm{~mol}^{-1}$, allowing one to identify mixtures composed of [ $\left.\mathrm{C}_{4} \mathrm{C}_{1} \mathrm{im}\right][\mathrm{DMP}],\left[\mathrm{C}_{4} \mathrm{C}_{1} \mathrm{im}\right]\left[\mathrm{NTf}_{2}\right]$ or $\left[\mathrm{C}_{4} \mathrm{C}_{1} \mathrm{im}\right]\left[\mathrm{PF}_{6}\right]$ with the selected protic ILs, as those with the highest potential. In fact, these mixtures present excess enthalpies two to three times higher than those obtained for mixtures composed only by protic or aprotic ILs. Overall, mixtures of $\left[\mathrm{C}_{4} \mathrm{C}_{1}\right.$ im] [DMP] and [DEEA] cationbased ILs present the highest excess enthalpy values. According with the work of Omar et al. [22] mixtures of ILs with similar ionic constituents may lead to exothermic or an almost ideal mixing phenomena, i.e., excess enthalpy close to zero, while IL - IL mixtures with significant structural differences lead to systems with large deviations from ideality with endothermic mixing phenomena.

The selection was then narrowed down to seven systems (Fig. 2), for further physicochemical characterization. The systems [BHEA] $[$ Ace $]+\left[\mathrm{C}_{4} \mathrm{C}_{1} \mathrm{im}\right][\mathrm{DMP}]$ and $[\mathrm{BHEA}][$ Ace $]+\left[\mathrm{C}_{4} \mathrm{C}_{1} \mathrm{im}^{\mathrm{im}}\right]\left[\mathrm{NTf}_{2}\right]$ were also included to explore the impact of changing the protic cation and the aprotic anion.

\subsection{Physicochemical properties}

\subsubsection{Density of the pure ionic liquids}

Densities $(\rho)$ of the pure ILs (water mass fractions lower than 1000 ppm) were measured and are presented in Fig. 3 and Table S3, along with the water content. Increasing temperature leads to an increase in the molecular mobility and thus to a decrease in the molecular packing and consequently in density. For each series, i.e., [DEEA] $\left.[\mathrm{X}](\mathrm{X}=\text { But or Pent) and [DEEA][H(Y) })_{2}\right](\mathrm{Y}=$ Ace, Prop or Hex), the increase of the protic anion chain length leads to a decrease in the density, as observed before [34]. This property follows the decreasing order of the molecular weight of the anions within the same series.

Gong et al. [36], Almeida et al. [37] and Hiraga et al. [38] were some of the authors reporting the density of $\left[\mathrm{C}_{4} \mathrm{C}_{1}\right.$ im] [DMP] at different temperatures. An average relative deviation, \%ARD $=1$ / $N \sum_{i=1}^{N}\left|\left(X^{\exp }-X^{\text {lit }}\right) / X^{\exp }\right|$ (where $X$ represents the property and the

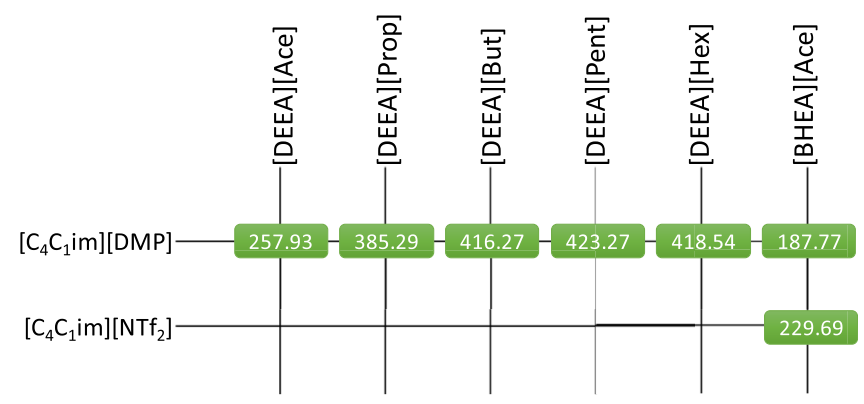

Fig. 2. ILs mixtures selected and respective excess enthalpies $\left(\mathrm{J} \cdot \mathrm{mol}^{-1}\right)$ predicted by COSMO-RS at $298.15 \mathrm{~K}$ and equimolar composition.

subscripts exp and lit the experimental and literature values, respectively), between the experimental values and those reported in the literature of $0.2 \%$ was here observed. Regarding $\left[\mathrm{C}_{4} \mathrm{C}_{1} \mathrm{im}\right]$ $\left[\mathrm{NTf}_{2}\right.$ ], an \%ARD of $0.1 \%$ was obtained in relation with literature [37,39-41]. To the best of our knowledge the protic ILs densities are here reported for the first time.

The Gardas and Coutinho model [35], an extension of the Ye and Shreeve group contribution method [42], was used to describe the experimental density data:

$\rho=\frac{M w}{N \cdot V(a+b \cdot T+c \cdot p)}$

where $\rho$ is the density in $\mathrm{kg} \cdot \mathrm{m}^{-3}, M w$ is the molecular weight in $\mathrm{kg} \cdot \mathrm{mol}^{-1}, N$ is the Avogadro constant, and $V$ is the volume in $\mathrm{m}^{3}$. The volume is assumed as the linear sum of the volumes of cation and anion [35]. $a, b$ and $c$ are coefficients previously proposed: $a=0.8005 \pm 0.0002, b=(6.652 \pm 0.007) \times 10^{-4} \mathrm{~K}^{-1}$ and $c=$ $(-5.919 \pm 0.024) \times 10^{-4} \mathrm{MPa}^{-1}$ [35]. $T$ and $p$ are the absolute temperature in $\mathrm{K}$ and the pressure in $\mathrm{MPa}$, respectively. The cation and anion volumes were taken from literature: $\left[C_{4} C_{1} \text { im }\right]^{+} 238 \AA^{3}$ [35]; [DMP] $139 \AA^{3}$ [43]; [NTf $]^{-} 248 \AA^{3}$ [35]; [Ace]- $83.5 \AA^{3}$ [34]; [Prop] $112.5 \AA^{3}$ [34]; [But] ${ }^{-} 141.5 \AA^{3}$ [34]; [Pent] $]^{-} 170.5 \AA^{3}$ [34]; $[\text { Hex }]^{-} 199.5 \AA^{3}$ [34]. The volumes of $\left[\mathrm{H}(\text { Ace })_{2}\right]^{-},\left[\mathrm{H}(\text { Prop })_{2}\right]^{-}$and $\left[\mathrm{H}(\mathrm{Hex})_{2}\right]^{-}$were estimated from the values of $[\text {Ace }]^{-}$, [Prop $]^{-},[\mathrm{Hex}]^{-}$ and $\mathrm{H}\left(5 \AA^{3}\right)$ [35]. The volumes of the cations [DEEA $]^{+}$and $[\mathrm{BHEA}]^{+}$,

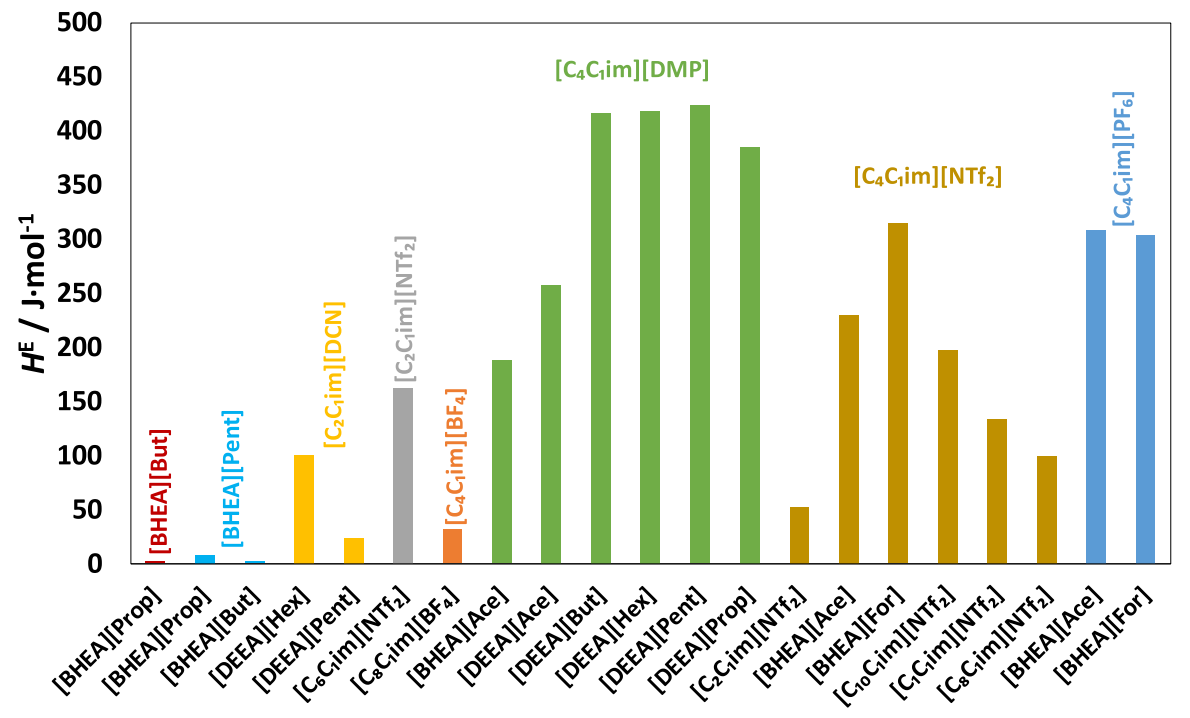

Fig. 1. Binary equimolar mixtures with positive excess enthalpies, $H^{\mathrm{E}}$, lower than $500 \mathrm{~J} \mathrm{~mol}^{-1}$ at $298.15 \mathrm{~K}$, computed by COSMO-RS. 

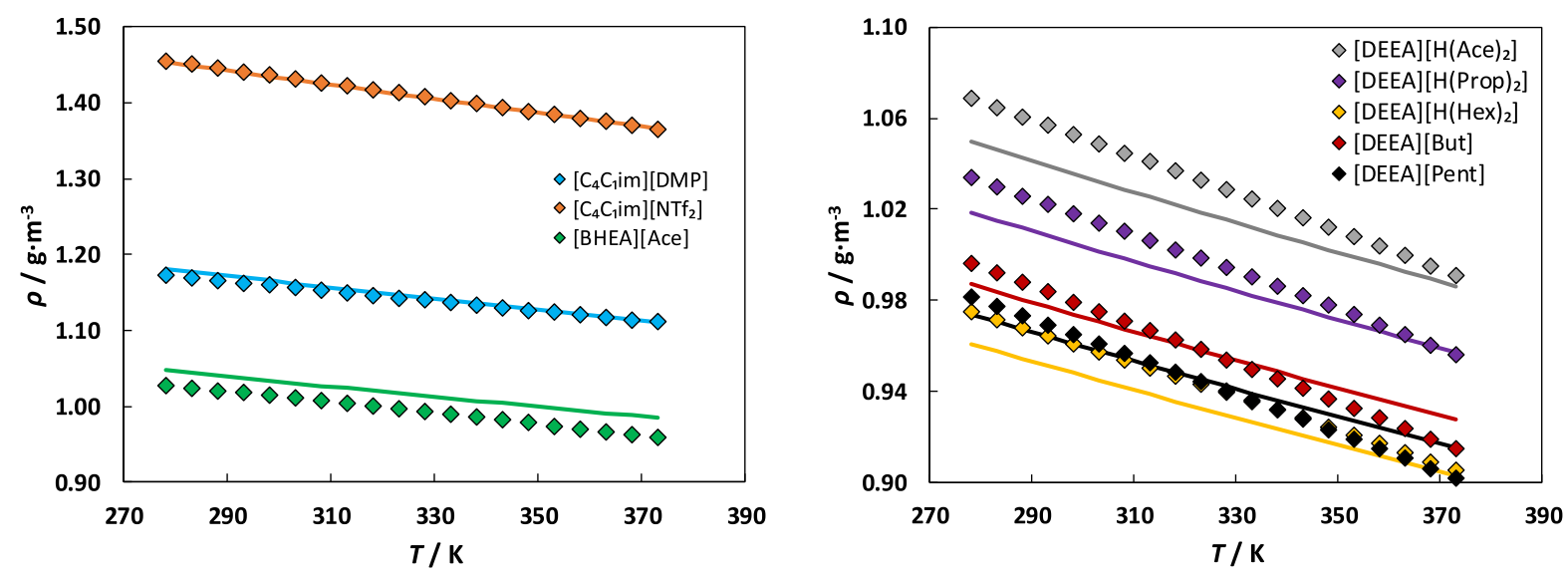

Fig. 3. Density of the pure ILs as function of temperature and predictions (solid lines) using Gardas and Coutinho [35] model.

209 and $201.5 \AA^{3}$, were obtained by adding the contribution of $-\mathrm{CH}_{2}-$ group, $28 \AA^{3}$, reported by Ye and Shreeve [42] to the molecular volume of $N, N$-dimethylethanolammonium [34] and $N$ methyl-2-hydroxyethylammonium [44] cations.

The percentage average relative deviations between the predicted densities, using the above mentioned model, and the experimental data were: $0.26 \%,\left[\mathrm{C}_{4} \mathrm{C}_{1} \mathrm{im}\right][\mathrm{DMP}]$; $0.12 \%,\left[\mathrm{C}_{4} \mathrm{C}_{1} \mathrm{im}\right]$ $\left[\mathrm{NTf}_{2}\right] ; 1.25 \%,[\mathrm{DEEA}]\left[\mathrm{H}(\text { Ace })_{2}\right] ; 0.85 \%,[\mathrm{DEEA}]\left[\mathrm{H}(\text { Prop })_{2}\right] ; 0.99 \%$, [DEEA][H(Hex $\left.)_{2}\right] ; 0.60 \%$, [DEEA][But]; 0.60\%, [DEEA][Pent] and $2.12 \%$, [BHEA][Ace]. The model can correctly predict the densities of the aprotic ILs in all the temperatures investigated. Regarding the protic ILs, significant differences can be observed namely for compound containing small anions. Additionally, from Fig. 3 it can be seen that for all protic ILs the model predicts a different temperature dependency compared to the experimental.

From the linear dependency of the density with temperature ( $\ln \rho=A_{0}+A_{1} T$, where $A_{0}$ and $A_{1}$ are fitting parameters and $T$ is the absolute temperature), the isobaric thermal expansion coefficient, $\alpha_{\mathrm{p}}$, can be calculated according to:

$\alpha_{p}=-\frac{1}{\rho}\left(\frac{\partial \rho}{\partial T}\right)_{p}=-\left(\frac{\partial \ln \rho}{\partial T}\right)_{p}=-A_{1}$

In the temperature range investigated in this work, the use of a linear regression to describe the experimental data is satisfactory, being the average relative deviation between the experimental and calculated values of $0.04 \%$.

Table 2 reports the thermal expansion coefficients at $0.1 \mathrm{MPa}$. For $[D E E A]^{+}$based ILs, the thermal expansion coefficient decreases while increasing the molecular weight of the protic IL, apart from [DEEA][H(Ace $\left.)_{2}\right]$ (Fig. S3). Additionally, protic [DEEA][X] ILs show

Table 2

Thermal expansion coefficients of the studied ionic liquids along with the expanded uncertainty with a $95 \%$ level of confidence.

\begin{tabular}{|c|c|}
\hline Ionic Liquid & $\left(10^{4} \times \alpha_{\mathrm{p}} \pm \sigma\right) / \mathrm{K}^{-1}$ \\
\hline$\left[\mathrm{C}_{4} \mathrm{C}_{1} \mathrm{im}\right][\mathrm{DMP}]$ & $5.72 \pm 0.01$ \\
\hline$\left[\mathrm{C}_{4} \mathrm{C}_{1} \mathrm{im}\right]\left[\mathrm{NTf}_{2}\right]$ & $6.70 \pm 0.01$ \\
\hline$[\mathrm{DEEA}]\left[\mathrm{H}(\text { Ace })_{2}\right]$ & $7.91 \pm 0.05$ \\
\hline$[$ DEEA $]\left[\mathrm{H}(\text { Prop })_{2}\right]$ & $8.17 \pm 0.07$ \\
\hline$[\mathrm{DEEA}]\left[\mathrm{H}(\mathrm{Hex})_{2}\right]$ & $7.82 \pm 0.05$ \\
\hline [DEEA][But] & $8.97 \pm 0.04$ \\
\hline [DEEA][Pent] & $8.90 \pm 0.04$ \\
\hline [BHEA][Ace] & $7.32 \pm 0.05$ \\
\hline
\end{tabular}

greater values of $\alpha_{\mathrm{p}}$ than the [DEEA][H(Y) $)_{2}$. These coefficients are a measure of how the volume changes with temperature and thus, this behavior is related to the packing of the hydrocarbon chains.

\subsubsection{Densities of the ILs mixtures}

The ILs mixtures densities, at different temperatures and compositions, are presented in Table S4 and depicted in Fig. 4. As expected, the density of the mixtures investigated decreases with increasing temperature and increases with the increase of the molar fraction of $\left[\mathrm{C}_{4} \mathrm{C}_{1} \mathrm{im}\right][\mathrm{DMP}]$ or $\left[\mathrm{C}_{4} \mathrm{C}_{1} \mathrm{im}\right]\left[\mathrm{NTf}_{2}\right]$, the denser compounds in the mixtures. At $298.15 \mathrm{~K}$ and equimolar composition, the mixture density decreases with the increase numbers of methyl groups in the protic IL anion in each series (Fig. 4-h). Regarding the anion, mixtures involving $\left[\mathrm{C}_{4} \mathrm{C}_{1} \mathrm{im}\right]\left[\mathrm{NTf}_{2}\right]$ are denser than mixtures with $\left[\mathrm{C}_{4} \mathrm{C}_{1} \mathrm{im}\right][\mathrm{DMP}]$. The mentioned conclusions are in line with the densities of the pure ionic liquids investigated.

In order to better understand the nature of the molecular interactions in the binary mixtures, the excess molar volumes $\left(V^{\mathrm{E}}\right)$ were estimated according to the equation:

$V^{E}=\frac{x_{1} M_{1}+x_{2} M_{2}}{\rho_{m}}-\frac{x_{1} M_{1}}{\rho_{1}}-\frac{x_{2} M_{2}}{\rho_{2}}$

where $x, M$ and $\rho$ represent the mole fractions, molar masses and densities, respectively, of the mixture, $m$, or of the components $(i=1,2)$.

Excess molar volumes result from physical and chemical interactions as well as structural contributions. While physical interactions involving weak dipole-dipole or dispersion forces increase the $V^{\mathrm{E}}$, chemical interactions and structural contributions decrease the $V^{E}$ [45]. In Fig. 5 the excess molar volumes as function of the protic IL mole fraction $\left(x_{1}\right)$ and temperature are depicted for the seven binary mixtures composed by the protic and aprotic ILs investigated.

The excess molar volumes were fitted to the Redlich-Kister [46] equation:

$V_{m}^{E}=x_{1}\left(1-x_{1}\right) \sum_{i=1}^{4}\left[A_{i}(T)\left(2 x_{1}-1\right)^{i-1}\right]$ 

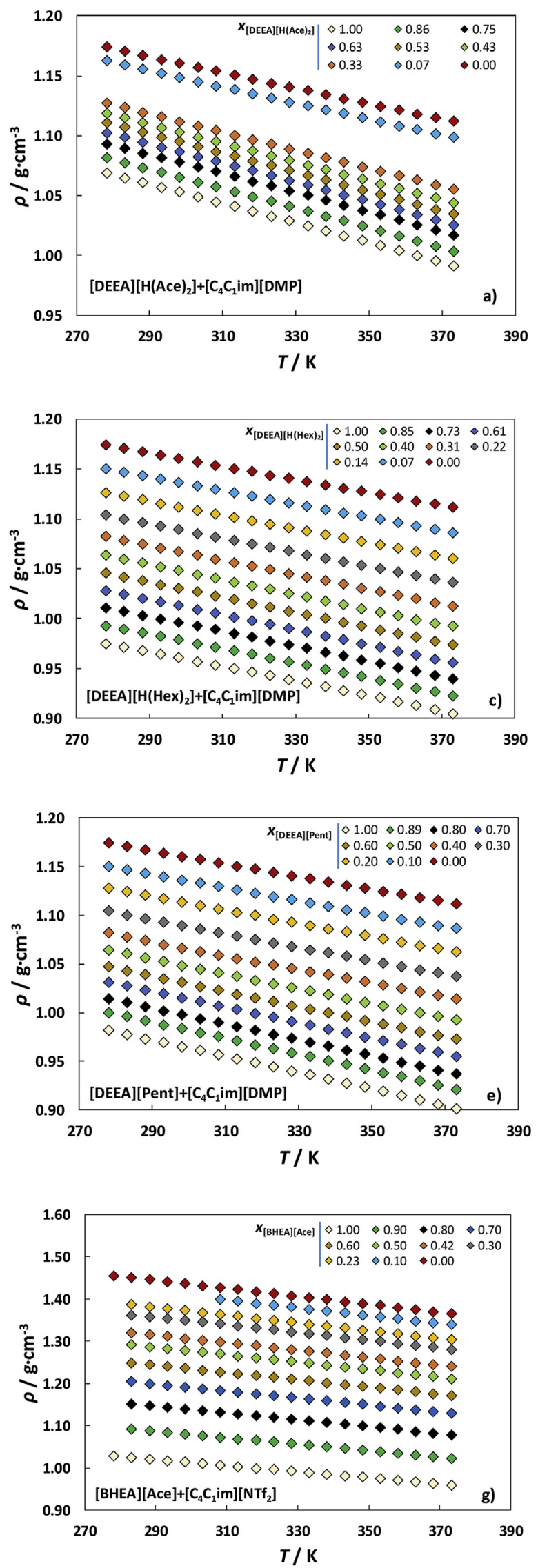
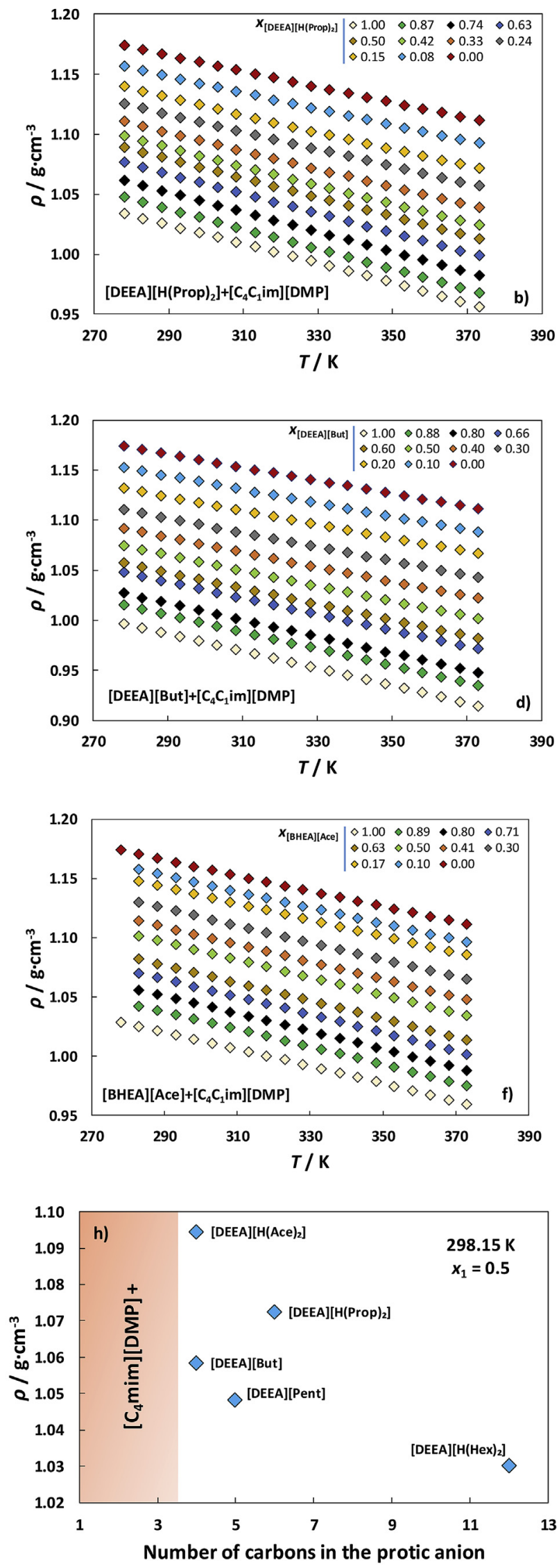

Fig. 4. Densities of the investigated mixtures as a function of temperature and composition. 

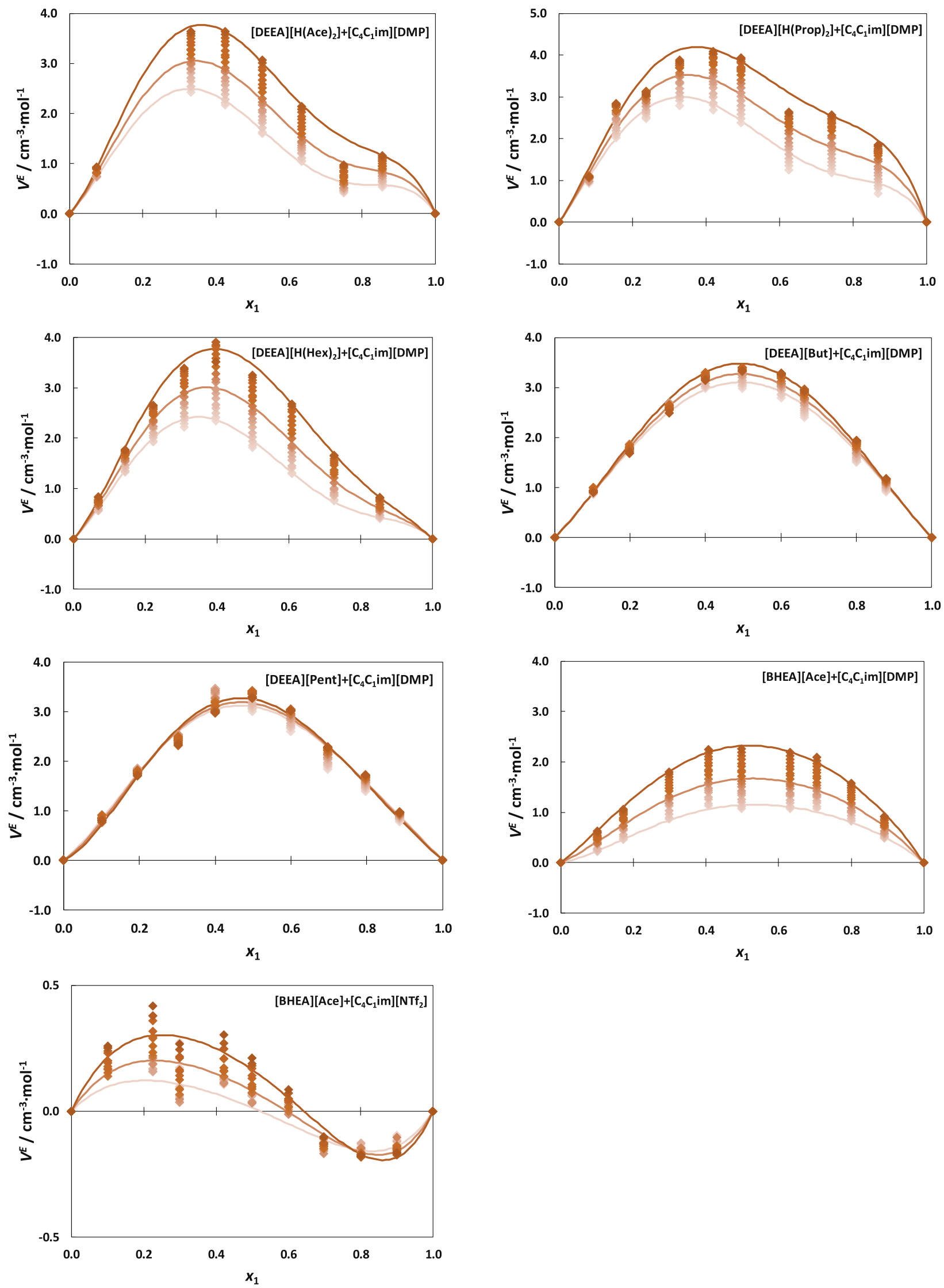

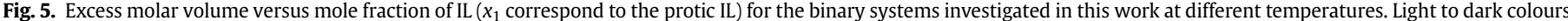
correspond to low to high temperatures (283.15-373.15) K. Solid lines represent the Redlich-Kister equation at 283.15, 323.15 and $373.15 \mathrm{~K}$. 
$A_{i}(T)=a_{i}+b_{i}(T / K)$

and

$\sigma=\left[\sum_{i=1}^{4} \frac{\left(V_{\exp }^{E}-V_{\text {calc }}^{E}\right)_{i}^{2}}{n-k}\right]^{1 / 2}$

where the values of the parameters $\left(a_{i}\right.$ and $\left.b_{i}\right)$ were determined using the method of least-squares, $\sigma$ is the standard deviation, $n$ is the number of experimental points and $k$ is the number of coefficients. The parameters are summarized in Table S5 along with the standard deviations of the fit, and the predicted lines at 283.15, 323.15 and $373.15 \mathrm{~K}$ are plotted in Fig. 5. Despite some discrepancies, the model is able to correctly describe the excess molar volumes at different temperatures and compositions.

The excess molar volumes of mixtures involving $\left[\mathrm{C}_{4} \mathrm{C}_{1} \mathrm{im}\right][\mathrm{DMP}]$ are positive over the whole range of compositions and temperatures denoting less favorable interactions between the species when compared to the pure compounds. Moreover, this suggests more free space in these mixtures making them good candidates for $\mathrm{CO}_{2}$ capture. The high values may be attributed to physical interactions that are not compensated by the weak interactions between different molecules. When composed by chemically distinct anions and cations, mixtures of ionic liquids have their first solvation sphere disrupted by the different species increasing the possibility of larger enthalpies of mixing [47]. The mixture involving $\left[\mathrm{C}_{4} \mathrm{C}_{1} \mathrm{im}\right]\left[\mathrm{NTf}_{2}\right]$ shows an inversion in the sign from positive to negative at $x_{1} \geq 0.55$. This means that the interactions between the ILs increase with the concentration of the protic IL.

The larger positive $V^{E}$ values were observed for mixtures containing diacetate, dipropanoate and dihexanoate indicating more free space between the molecules when using [DEEA][H(Y) $\left.)_{2}\right]$ ILs. These three mixtures present asymmetrical $V^{\mathrm{E}}(x)$ curves with a maximum around mole fractions of 0.33 of protic IL. Regarding the other mixtures they all present symmetrical $V^{\mathrm{E}}(x)$ curves, with positive $V^{\mathbb{E}}$. The increase of temperature makes the excess molar volume more positive, indicating that the mixture is more expansible than the pure compounds. Exceptions are [DEEA][But]+

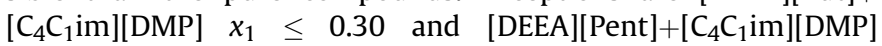
$x_{1} \leq 0.40$, where the opposite behavior is observed.

When comparing the magnitude of the deviation from ideality observed experimentally to that obtained from COSMO-RS predictions at $298.15 \mathrm{~K}$ and $x_{1}=0.5$ (Fig. 1), for mixtures involving $\left[\mathrm{C}_{4} \mathrm{C}_{1} \mathrm{im}\right][\mathrm{DMP}]$ the model is able to correctly predict that the $V^{\mathrm{E}}$ of [DEEA][But] $+\left[\mathrm{C}_{4} \mathrm{C}_{1}\right.$ im] $[\mathrm{DMP}]$ is approximately equal to that of [DEEA $][$ Pent $]+\left[\mathrm{C}_{4} \mathrm{C}_{1}\right.$ im] $][$ DMP]. Regarding [BHEA $][$ Ace $]+\left[\mathrm{C}_{4} \mathrm{C}_{1}\right.$ im] [NTf ${ }_{2}$ ] COSMO-RS fails, predicting an excess enthalpy for this mixture higher than for [BHEA][Ace] $+\left[\mathrm{C}_{4} \mathrm{C}_{1}\right.$ im] [DMP]. Overall, this predictive tool is a valuable utensil for a preliminary quick screen allowing to identify the ionic liquids families with the highest potential for $\mathrm{CO}_{2}$ capture.

The positive excess molar volumes found in literature for IL mixtures are in general small and very close to zero. The first extensive work on this was reported by Rebelo et al. [48] that studied the volumes of mixing of mixtures of imidazolium-based ILs containing $\left[\mathrm{NTf}_{2}\right]^{-},\left[\mathrm{BF}_{4}\right]^{-}$or $\left[\mathrm{PF}_{6}\right]^{-}$anions. All mixtures were found to have small positive $V^{\mathrm{E}}$, i.e., an almost linear mixing behavior. In their review from 2012, Niedermeyer et al. [49] cite several works on the subject and all are described as small and positive (or negative). Thereafter, many works were published. Annat et al. [50] for example measured the $V^{E}$ of mixtures of $\left[\mathrm{C}_{3} \mathrm{mpyr}\right]\left[\mathrm{NTf}_{2}\right]$ and 5 other ILs obtaining also small positive excess molar volumes in the order of $[-0.3$ to 1.8$] \mathrm{cm}^{3} \cdot \mathrm{mol}^{-1}$. Clough et al. [47] examined the physical properties of ten mixtures covering different types of cations and anions, however, also here $V^{\mathrm{E}}<1.4 \mathrm{~cm}^{3} \mathrm{~mol}^{-1}$ were achieved. More recently, Brooks et al. [51] tried to establish the relationship between the structures, free volumes and properties of ILs mixtures. They investigated several mixtures of ILs and once more, excess molar volumes were found to be small and positive (or negative). To the best of our knowledge, the excess molar volumes of the mixtures investigated in this work are by far the highest reported to date promoting their use and application.

\subsubsection{Viscosity of the pure ionic liquids}

Due to their impact in mass transport phenomena, viscosity is a very important property, in particular for $\mathrm{CO}_{2}$ capture. Small viscosities increase the mass transfer coefficients leading to a fast diffusion of $\mathrm{CO}_{2}$ to the liquid bulk. The experimental viscosity $(\eta)$ of the pure ILs investigated (water mass fractions lower than $1000 \mathrm{ppm}$ ) as function of temperature are listed in Table S3 and shown in Fig. 6.

The ILs viscosity temperature dependency, generally depends on intermolecular interactions like $\mathrm{H}$-bonding and dispersive and Coulombic interactions and these interactions decrease with increase temperature [52]. Thus, and as expected, viscosity decreases with increasing temperature. For instance, for [DEEA][H(Ace $\left.)_{2}\right]$ a rise in temperature from 278.15 to $373.15 \mathrm{~K}$ leads to a fall in viscosity from 339.51 to $4.50 \mathrm{mPa}$ s. At $278.15 \mathrm{~K}$, the viscosities follow the trend: [BHEA][Ace] $>\left[\mathrm{C}_{4} \mathrm{C}_{1}\right.$ im] [DMP] $>$ [DEEA] $\left.[\text { H(Ace })_{2}\right]>[$ DEEA $\left.][\text { H(Prop })_{2}\right]>$ [DEEA $][$ But $]>$ [DEEA] $\left[\mathrm{H}(\mathrm{Hex})_{2}\right]>[$ DEEA $][$ Pent $]>\left[\mathrm{C}_{4} \mathrm{C}_{1}\right.$ im $]\left[\mathrm{NTf}_{2}\right]$; while at $373.15 \mathrm{~K}$ : $\left[\mathrm{C}_{4} \mathrm{C}_{1} \mathrm{im}\right][\mathrm{DMP}]>[\mathrm{BHEA}][$ Ace $]>\left[\mathrm{C}_{4} \mathrm{C}_{1} \mathrm{im}^{\mathrm{im}}\right]\left[\mathrm{NTf}_{2}\right]>[\mathrm{DEEA}]$ $\left[\mathrm{H}(\mathrm{Hex})_{2}\right]>[$ DEEA $]\left[\mathrm{H}(\text { Ace })_{2}\right]>[$ DEEA $]\left[\mathrm{H}(\text { Prop })_{2}\right]>[$ DEEA $]$ [But] $>$ [DEEA][Pent]. For the investigated compounds with a common cation and within the same series ([DEEA][X] and [DEEA] $\left[\mathrm{H}(\mathrm{Y})_{2}\right]$ ), viscosity decreases with the increase of the alkyl side chain length of the anion. At room temperature [DEEA]-based ILs and $\left[\mathrm{C}_{4} \mathrm{C}_{1} \mathrm{im}\right]\left[\mathrm{NTf}_{2}\right]$ present small viscosities making them more interesting for industrial applications.

Compared to density, in general larger deviations between sets of data by different authors are observed for viscosity. The differences are usually due to the well-known impact of water in this property [53]. Among others, Gong et al. [36] and Hiraga et al. [38] reported the viscosity of $\left[\mathrm{C}_{4} \mathrm{C}_{1} \mathrm{im}\right][\mathrm{DMP}]$ between 293 and $373 \mathrm{~K}$. An average relative deviation of 3.7 and $9.2 \%$, respectively, to the data here published is observed. While in this work $\left[\mathrm{C}_{4} \mathrm{C}_{1} \mathrm{im}\right][\mathrm{DMP}]$ was dried and manipulated under a dry atmosphere in order to avoid water absorption, Gong et al. [36] for example do no mention any special care or the water content of the sample used in their measurements. The experimental viscosity values for pure $\left[\mathrm{C}_{4} \mathrm{C}_{1} \mathrm{im}\right]$ $\left[\mathrm{NTf}_{2}\right]$ measured in this work are in good agreement with the values reported by Hiraga et al. [38] $(\% A R D=1.3)$ and Liu et al. [41] $(\% A R D=4.1)$.

The viscosities of pure ILs were fitted according the Vogel-Tammann-Fulcher (VTF) model [53], expressed by equation (7). Based on the viscosity dependence with the temperature, the energy barrier, $E$, was derived through equation (8).

$$
\begin{aligned}
& \eta(T)=A_{\eta} \exp \left[\frac{B_{\eta}}{T-C_{\eta}}\right] \\
& E=R \frac{\partial(\ln [\eta(T)])}{\partial(1 / T)}
\end{aligned}
$$

where $A_{\eta}, B_{\eta}$, and $C_{\eta}$ are adjustable parameters (Table 3 ) estimated 

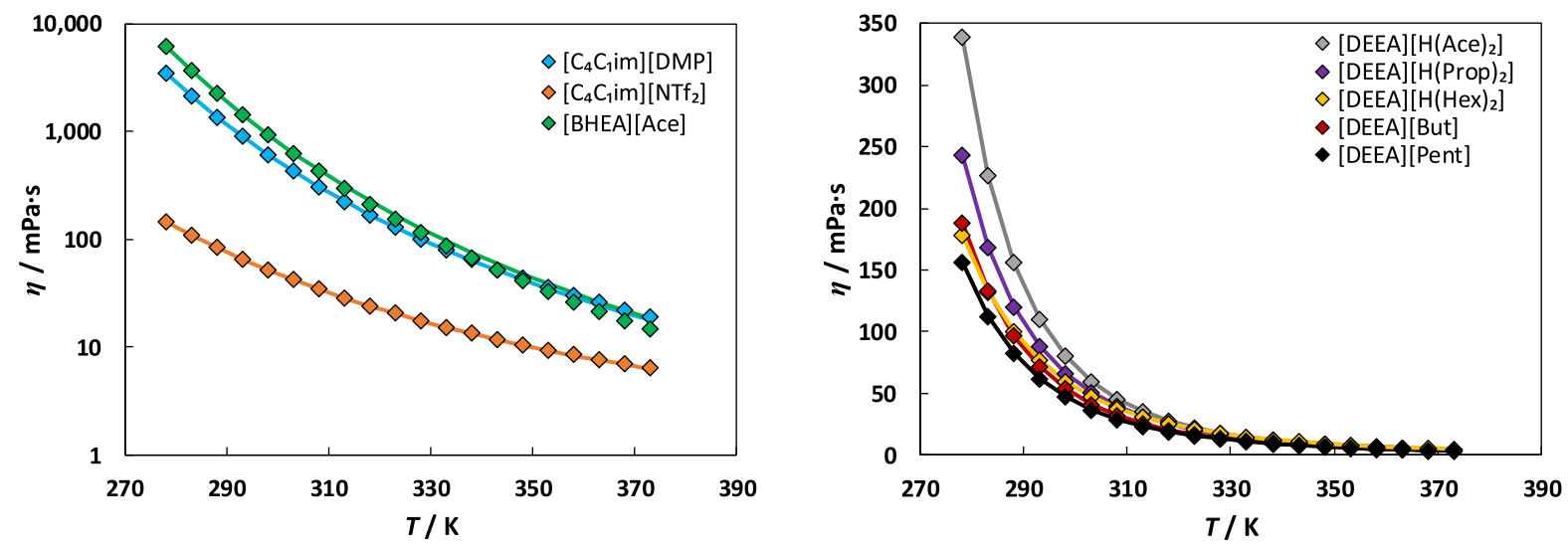

Fig. 6. Viscosities of the pure ILs as function of temperature and calculated values (solid lines) using the VTF equation.

from experimental data and $R\left(\mathrm{~J} \cdot \mathrm{K}^{-1} \cdot \mathrm{mol}^{-1}\right)$ is the ideal gas constant.

Results show that the application of the VTF correlation provides a good description of the viscosity dependence, as depicted in Fig. 6 and Table 3. The only exception is observed for [BHEA][Ace] with an \%ARD of about $10 \%$. This may be explained by the enormous difference of the viscosity values at 278 and $373 \mathrm{~K}$. The differences in viscosity translate into different values of $E$; higher the viscosity, higher the energy barrier of a fluid to shear stress and harder it is for the ions to move past each other. At $298.15 \mathrm{~K}$, [BHEA][Ace] is the ionic liquid with highest $E$, followed by $\left[\mathrm{C}_{4} \mathrm{C}_{1} \mathrm{im}\right][\mathrm{DMP}]$ while $\left[\mathrm{C}_{4} \mathrm{C}_{1} \mathrm{im}\right]\left[\mathrm{NTf}_{2}\right]$ presents the lowest value. Thus, $\left[\mathrm{C}_{4} \mathrm{C}_{1} \mathrm{im}\right]\left[\mathrm{NTf}_{2}\right]$ is the IL that require less energy to move freely in the bulk, whereas [BHEA][Ace] and $\left[\mathrm{C}_{4} \mathrm{C}_{1}\right.$ im] [DMP] are those that need the more energy. This may be explained by the size of the species, their symmetry and cation-anion interactions. Regarding the [DEEA]-based cations, the energy barrier decreases while increasing the cation chain length within the same series.

\subsubsection{Viscosities of the ILs mixtures}

The viscosity data for the selected binary mixtures of ILs are depicted in Fig. 7 (versus temperature) and 8 (versus compositions) and listed in Table S6. Such as for density, viscosity decrease with increasing temperature. Moreover, it increases with the increasing concentration of the $\left[\mathrm{C}_{4} \mathrm{C}_{1}\right.$ im] [DMP], excepting the [BHEA] $[$ Ace $]+\left[\mathrm{C}_{4} \mathrm{C}_{1} \mathrm{im}\right][\mathrm{DMP}]$ system where this only happens for temperatures higher than $338.15 \mathrm{~K}$. In [BHEA][Ace] $+\left[\mathrm{C}_{4} \mathrm{C}_{1}\right.$ im] $\left[\mathrm{NTf}_{2}\right]$ viscosity decreases with the increase of the aprotic IL due to their small viscosity when compared with the protic [BHEA][Ace]. Unlike densities, viscosities do not vary linearly with the number of carbons in the protic anion - Fig. 7-h.

The non-ideality of the mixtures investigated was assessed using the Grunberg and Nissan [54] mixing law where an additional parameter to account for non-ideality, $G_{12}$, was included:

$\ln \eta_{m}=x_{1} \ln \eta_{1}+x_{2} \ln \eta_{2}+x_{1} x_{2} G_{12}(T)$

The optimum parameters determined for the studied mixtures are reported in Table S7 and Fig. 8 as function of temperature. As it can be seen in Fig. 8, a good description of the experimental data in all the composition ranges and temperatures was obtained.

The parameter $G_{12}$ allows to quantify and express the deviations of the mixtures viscosity in relation to ideality (meaning $G_{12}=0$ ) reported in Fig. S4. Due to the chemical and size differences between the ILs, the systems investigated exhibit negative deviations from the ideal Grunberg and Nissan mixing law. Larger deviations are observed at low temperatures. [BHEA][Ace] $+\left[\mathrm{C}_{4} \mathrm{C}_{1}\right.$ im] $\left[\mathrm{NTf}_{2}\right]$ are the mixtures closer to ideal behavior, especially at high temperatures, presenting a linear dependency of $G_{12}$ with temperature - Fig. 8-h. This is in agreement with the work of Almeida et al. [37] where the mixture of $\left[\mathrm{C}_{4} \mathrm{C}_{1} \mathrm{im}\right][$ Ace $]+\left[\mathrm{C}_{4} \mathrm{C}_{1}\right.$ im $]\left[\mathrm{NTf}_{2}\right]$ that contains the same anions follows almost an ideal behavior.

\section{Conclusions}

This work contributes for the identification of promising mixture of ionic liquids to be used for the development of a costefficient $\mathrm{CO}_{2}$ capture process. COSMO-RS was used to search for mixtures of ILs with positive excess enthalpies. Seven mixtures composed of $\left[\mathrm{C}_{4} \mathrm{C}_{1} \mathrm{im}\right][\mathrm{DMP}]$ or $\left[\mathrm{C}_{4} \mathrm{C}_{1} \mathrm{im}\right]\left[\mathrm{NTf}_{2}\right]$, and carboxylatebased protic ILs, were selected and characterized by measuring their densities and viscosities at different temperatures and in the whole composition range. In general, large positive excess molar volumes and low viscosities were obtained for mixtures involving

Table 3

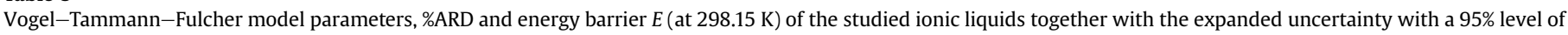
confidence.

\begin{tabular}{|c|c|c|c|c|c|}
\hline Ionic Liquid & $\left(\boldsymbol{A}_{\eta} \pm \sigma\right) / \mathrm{mPa} \cdot \mathrm{s}$ & $\left(\boldsymbol{B}_{\eta} \pm \sigma\right) / \mathrm{K}$ & $\left(\boldsymbol{C}_{\eta} \pm \sigma\right) / \mathrm{K}$ & \%ARD/\% & $\mathrm{E} / \mathrm{kJ} \cdot \mathrm{mol}^{-1}$ \\
\hline$\left[\mathrm{C}_{4} \mathrm{C}_{1} \mathrm{im}\right][\mathrm{DMP}]$ & $0.039 \pm 0.002$ & $1263.79 \pm 13.96$ & $167.47 \pm 0.66$ & 1.75 & $54.69 \pm 1.41$ \\
\hline$\left[\mathrm{C}_{4} \mathrm{C}_{1} \mathrm{im}\right]\left[\mathrm{NTf}_{2}\right]$ & $0.149 \pm 0.004$ & $779.62 \pm 6.95$ & $164.95 \pm 0.58$ & 0.32 & $32.48 \pm 0.70$ \\
\hline$[\mathrm{DEEA}]\left[\mathrm{H}(\text { Ace })_{2}\right]$ & $0.024 \pm 0.002$ & $1072.73 \pm 17.72$ & $165.70 \pm 1.03$ & 1.38 & $45.19 \pm 1.75$ \\
\hline$\left[\right.$ DEEA] $\left[\mathrm{H}(\text { Prop })_{2}\right]$ & $0.035 \pm 0.001$ & $1025.71 \pm 3.24$ & $162.36 \pm 0.20$ & 0.28 & $41.11 \pm 0.30$ \\
\hline$[\mathrm{DEEA}]\left[\mathrm{H}(\mathrm{Hex})_{2}\right]$ & $0.021 \pm 0.001$ & $1317.17 \pm 4.55$ & $132.53 \pm 0.28$ & 0.21 & $35.49 \pm 0.25$ \\
\hline$[$ DEEA $][$ But $]$ & $0.014 \pm 0.001$ & $1247.94 \pm 16.24$ & $146.63 \pm 0.95$ & 0.75 & $40.17 \pm 1.12$ \\
\hline [DEEA][Pent] & $0.015 \pm 0.001$ & $1253.33 \pm 14.92$ & $142.49 \pm 0.90$ & 0.60 & $38.23 \pm 0.96$ \\
\hline [BHEA][Ace] & $0.014 \pm 0.006$ & $1518.39 \pm 96.51$ & $161.12 \pm 4.00$ & 10.39 & $59.76 \pm 8.48$ \\
\hline
\end{tabular}



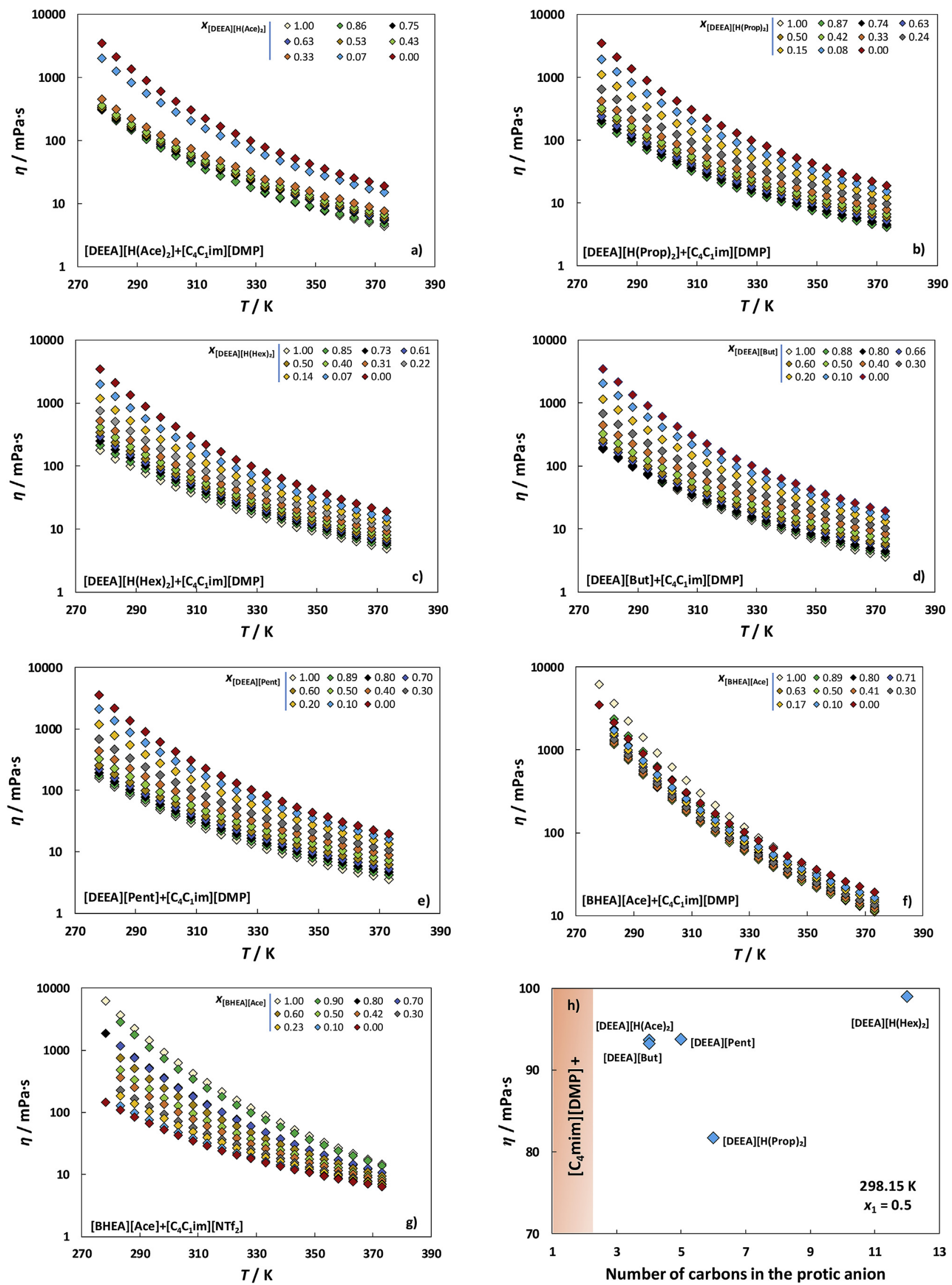

Fig. 7. Viscosity of studied mixtures, and the correspondent pure ILs, as a function of temperature and composition. 

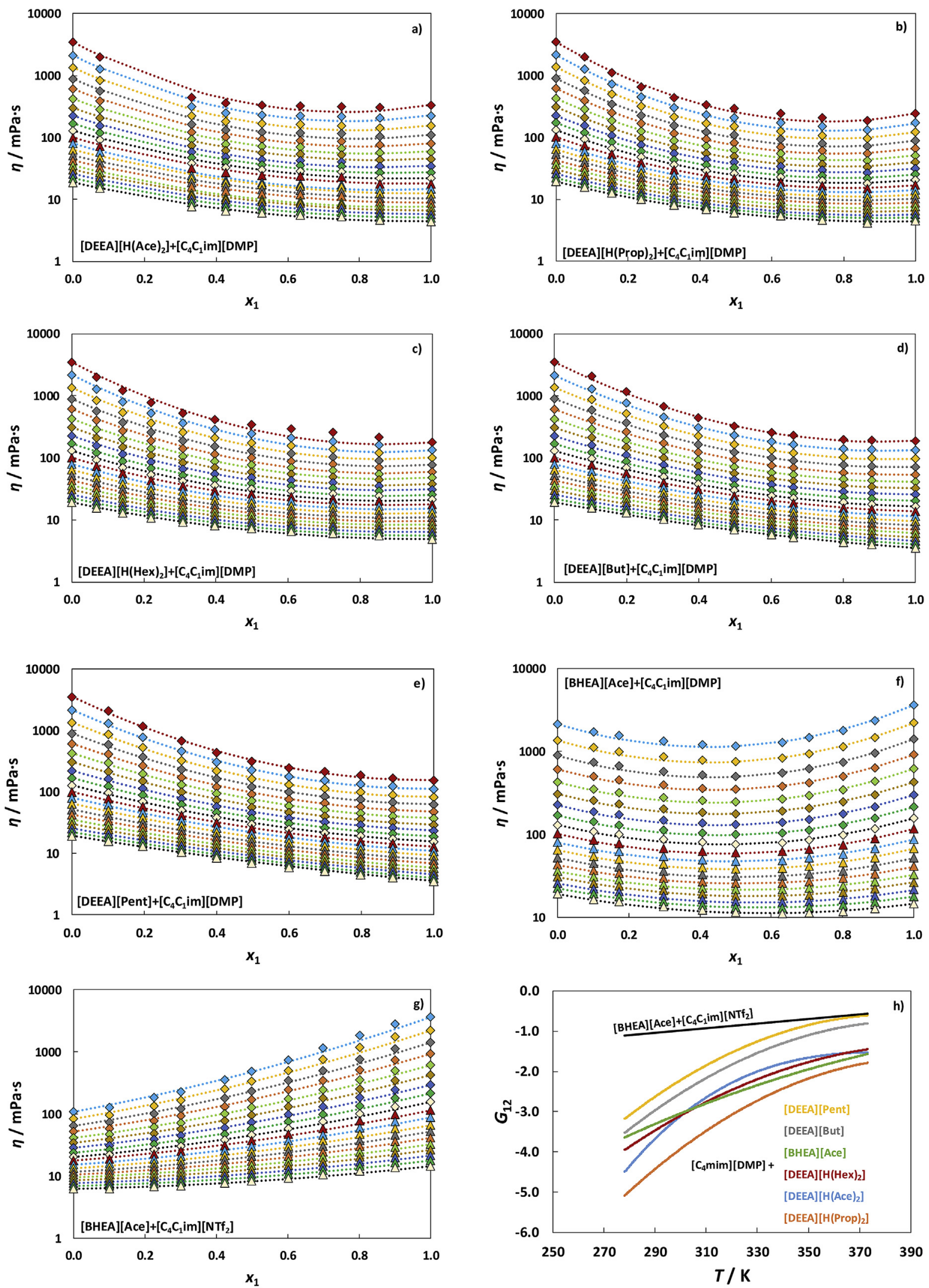

$\diamond 278.15 \diamond 283.15 \diamond 288.15 \diamond 293.15 \diamond 298.15 \diamond 303.15 \diamond 308.15 \diamond 313.15 \diamond 318.15 \diamond 323.15$

$\Delta 328.15 \Delta 333.15 \Delta 338.15 \Delta 343.15 \Delta 348.15 \Delta 353.15 \Delta 358.15 \Delta 363.15 \Delta 368.15 \Delta 373.15$

Fig. 8. Viscosity versus mole fraction of the protic IL at different temperatures. Symbols represent experimental values and the solid curves represent the Grunberg and Nissan predictions. 
$\left[\mathrm{C}_{4} \mathrm{C}_{1}\right.$ im] $]$ DMP] making them good candidates for $\mathrm{CO}_{2}$ capture. Thus, in this work it is shown the possibility to fine-tune the properties of ILs by mixing them to achieve low viscosities while keeping their sorption capacity.

\section{Declaration of competing interest}

The authors declare that they have no known competing financial interests or personal relationships that could have appeared to influence the work reported in this paper.

\section{Acknowledgements}

This work is a result of the Indo-Portuguese Program for Cooperation in Science \& Technology DST/INT/Portugal/P-01/2017, financed by FCT and the Government of India. This work was also developed within the scope of the project CICECO-Aveiro Institute of Materials, UIDB/50011/2020 \& UIDP/50011/2020, and CIMOMountain Research Center, UIDB/00690/2020, both financed by national funds through the FCT, MEC and when appropriate cofinanced by FEDER under the PT2020 Partnership Agreement. MARM acknowledges the project “AIProcMat@N2020 - Advanced Industrial Processes and Materials for a Sustainable Northern Region of Portugal 2020", with the reference NORTE-01-0145-FEDER000006, supported by Norte Portugal Regional Operational Programme (NORTE 2020). P.J.C. acknowledges FCT for his contract under the Investigator FCT 2015 contract number IF/00758/2015.

\section{Appendix A. Supplementary data}

Supplementary data to this article can be found online at https://doi.org/10.1016/j.fluid.2020.112621.

\section{References}

[1] J.D. Figueroa, T. Fout, S. Plasynski, H. Mcllvried, R.D. Srivastava, Advances in CO2 capture technology - the U.S. Department of energy's carbon sequestration program, Int. J. Greenh. Gas Control 2 (2008) 9-20, https://doi.org/ 10.1016/S1750-5836(07)00094-1.

[2] B.A. Oyenekan, G.T. Rochelle, Energy performance of stripper configurations for CO 2 capture by aqueous amines, Ind. Eng. Chem. Res. 45 (2006) 2457-2464, https://doi.org/10.1021/ie050548k.

[3] M. Hasib-ur-Rahman, M. Siaj, F. Larachi, Ionic liquids for $\mathrm{CO} 2$ captureDevelopment and progress, Chem. Eng. Process. Process Intensif. 49 (2010) 313-322, https://doi.org/10.1016/j.cep.2010.03.008.

[4] J. Gabrielsen, M.L. Michelsen, E.H. Stenby, G.M. Kontogeorgis, A model for estimating CO 2 solubility in aqueous alkanolamines, Ind. Eng. Chem. Res. 44 (2005) 3348-3354, https://doi.org/10.1021/ie048857i.

[5] A.D. Ebner, J.A. Ritter, State-of-the-art adsorption and membrane separation processes for carbon dioxide production from carbon dioxide emitting industries, Separ. Sci. Technol. 44 (2009) 1273-1421, https://doi.org/10.1080/ 01496390902733314.

[6] B.P. Mandal, M. Kundu, S.S. Bandyopadhyay, Physical solubility and diffusivity of $\mathrm{N} 2 \mathrm{O}$ and $\mathrm{CO} 2$ into aqueous solutions of (2-Amino-2-methyl-1-propanol + monoethanolamine) and (N-methyldiethanolamine + Monoethanolamine), J. Chem. Eng. Data 50 (2005) 352-358, https://doi.org/10.1021/je049826x.

[7] F. Barzagli, F. Mani, M. Peruzzini, A 13C NMR study of the carbon dioxide absorption and desorption equilibria by aqueous 2-aminoethanol and $\mathrm{N}$ methyl-substituted 2-aminoethanol, Energy Environ. Sci. 2 (2009) 322-330, https://doi.org/10.1039/b814670e.

[8] P.J. Carvalho, K.A. Kurnia, J.A.P. Coutinho, Dispelling some myths about the CO 2 solubility in ionic liquids, Phys. Chem. Chem. Phys. 18 (2016) 14757-14771, https://doi.org/10.1039/C6CP01896C.

[9] C. Wu, T.P. Senftle, W.F. Schneider, First-principles-guided design of ionic liquids for CO2 capture, Phys. Chem. Chem. Phys. 14 (2012) 13163-13170, https://doi.org/10.1039/c2cp41769c.

[10] R.D. Rogers, CHEMISTRY: ionic liquids-solvents of the future? Science 302 (2003) 792-793, https://doi.org/10.1126/science.1090313.

[11] B. Kirchner, Ionic Liquids, Springer-Verlag Berlin Heidelberg, Heidelberg, Germany, 2010.

[12] Z. Lei, J. Han, B. Zhang, Q. Li, J. Zhu, B. Chen, Solubility of $\mathrm{CO}_{2}$ in binary mixtures of room-temperature ionic liquids at high pressures, J. Chem. Eng. Data 57 (2012) 2153-2159, https://doi.org/10.1021/je300016q.

[13] H. Lin, B.D. Freeman, Materials selection guidelines for membranes that remove $\mathrm{CO} 2$ from gas mixtures, J. Mol. Struct. 739 (2005) 57-74, https:// doi.org/10.1016/j.molstruc.2004.07.045.

[14] A. Finotello, J.E. Bara, S. Narayan, D. Camper, R.D. Noble, Ideal gas solubilities and solubility selectivities in a binary mixture of room-temperature ionic liquids, J. Phys. Chem. B 112 (2008) 2335-2339, https://doi.org/10.1021/ jp0755721.

[15] D. Song, A.F. Seibert, G.T. Rochelle, Mass transfer parameters for packings: effect of viscosity, Ind. Eng. Chem. Res. 57 (2018) 718-729, https://doi.org/ 10.1021/acs.iecr.7b04396.

[16] A. Klamt, COSMO-RS from Quantum Chemistry to Fluid Phase Thermodynamics and Drug Design, Elsevier, Amsterdam, The Netherlands, 2005.

[17] L.Y. Wang, Y.L. Xu, Z.D. Li, Y.N. Wei, J.P. Wei, CO2/CH4 and H2S/CO2 selectivity by ionic liquids in natural gas sweetening, Energy Fuel. 32 (2018) 10-23. https://doi.org/10.1021/acs.energyfuels.7b02852.

[18] G.R.M. Dowson, D.G. Reed, J.-M. Bellas, C. Charalambous, P. Styring, Fast and selective separation of carbon dioxide from dilute streams by pressure swing adsorption using solid ionic liquids, Faraday Discuss 192 (2016) 511-527, https://doi.org/10.1039/C6FD00035E.

[19] A. Arce, M.J. Earle, S.P. Katdare, H. Rodríguez, K.R. Seddon, Application of mutually immiscible ionic liquids to the separation of aromatic and aliphatic hydrocarbons by liquid extraction: a preliminary approach, Phys. Chem. Chem. Phys. 10 (2008) 2538-2542, https://doi.org/10.1039/b718101a.

[20] G. Annat, M. Forsyth, D.R. MacFarlane, Ionic liquid mixtures-variations in physical properties and their origins in molecular structure, J. Phys. Chem. B 116 (2012) 8251-8258, https://doi.org/10.1021/jp3012602.

[21] A. Arce, M.J. Earle, S.P. Katdare, H. Rodríguez, K.R. Seddon, Mutually immiscible ionic liquids, Chem. Commun. (2006) 2548-2550, https://doi.org/ 10.1039/B604595B.

[22] S. Omar, J. Lemus, E. Ruiz, V.R. Ferro, J. Ortega, J. Palomar, Ionic liquid mixtures-an analysis of their mutual miscibility, J. Phys. Chem. B 118 (2014) 2442-2450, https://doi.org/10.1021/jp411527b.

[23] G. Sharma, D. Singh, S. Rajamani, R.L. Gardas, Influence of alkyl substituent on optical properties of carboxylate-based protic ionic liquids, ChemistrySelect 2 (2017) 10091-10096, https://doi.org/10.1002/slct.201701878.

[24] B.K. Chennuri, V. Losetty, R.L. Gardas, Apparent molar properties of hydroxyethyl ammonium based ionic liquids with water and ethanol at various temperatures, J. Mol. Liq. 212 (2015) 444-450, https://doi.org/10.1016/ j.molliq.2015.09.050.

[25] F.M.S. Ribeiro, C.F.R.A.C. Lima, A.M.S. Silva, L.M.N.B.F. Santos, Experimental evidence for azeotrope formation from protic ionic liquids, ChemPhysChem 19 (2018) 2364-2369, https://doi.org/10.1002/cphc.201800335.

[26] M. Yoshizawa, W. Xu, C.A. Angell, Ionic liquids by proton transfer: vapor pressure, conductivity, and the relevance of $\Delta \mathrm{pKa}$ from aqueous solutions, J. Am. Chem. Soc. 125 (2003) 15411-15419, https://doi.org/10.1021/ ja035783d.

[27] A. Klamt, F. Eckert, COSMO-RS: a novel and efficient method for the A prior prediction of thermophysical data of liquids, Fluid Phase Equil. 172 (2000) 43-72, https://doi.org/10.1016/S0378-3812(00)00357-5.

[28] University of Karlsruhe and Forschungszentrum Karlsruhe GmbH, TURBOMOLE V6.1 2009, 1989-2007, $25 \mathrm{GmbH}$, since, available from, http://www. turbomole.com, 2007.

[29] A.F.M. Claudio, L. Swift, J.P. Hallett, T. Welton, J.A.P. Coutinho, M.G. Freire, Extended scale for the hydrogen-bond basicity of ionic liquids, Phys. Chem. Chem. Phys. 16 (2014) 6593-6601, https://doi.org/10.1039/C3CP55285C.

[30] C. Moya, M. Gonzalez-Miquel, F. Rodriguez, A. Soto, H. Rodriguez, J. Palomar, Non-ideal behavior of ionic liquid mixtures to enhance $\mathrm{CO} 2$ capture, Fluid Phase Equil. 450 (2017) 175-183, https://doi.org/10.1016/j.fluid.2017.07.014.

[31] B.K. Chennuri, R.L. Gardas, Measurement and correlation for the thermophysical properties of hydroxyethyl ammonium based protic ionic liquids: effect of temperature and alkyl chain length on anion, Fluid Phase Equil. 427 (2016) 282-290, https://doi.org/10.1016/J.FLUID.2016.07.022.

[32] R. Vijayaraghavan, T. Oncsik, B. Mitschke, D.R. MacFarlane, Base-rich diamino protic ionic liquid mixtures for enhanced CO2 capture, Separ. Purif. Technol. 196 (2018) 27-31, https://doi.org/10.1016/J.SEPPUR.2017.06.057.

[33] X. Zhu, M. Song, Y. Xu, DBU-based protic ionic liquids for $\mathrm{CO}_{2}$ capture, ACS Sustain. Chem. Eng. 5 (2017) 8192-8198, https://doi.org/10.1021/ acssuschemeng.7b01839.

[34] G. Sharma, R.L. Gardas, A. Coronas, G. Venkatarathnam, Effect of anion chain length on physicochemical properties of N,N-dimethylethanolammonium based protic ionic liquids, Fluid Phase Equil. 415 (2016) 1-7, https:/| doi.org/10.1016/j.fluid.2016.01.036.

[35] R.L. Gardas, J.A.P. Coutinho, Extension of the Ye and Shreeve group contribution method for density estimation of ionic liquids in a wide range of temperatures and pressures, Fluid Phase Equil. 263 (2008) 26-32, https:// doi.org/10.1016/j.fluid.2007.09.016.

[36] Y. Gong, C. Shen, Y. Lu, H. Meng, C. Li, Viscosity and density measurements for six binary mixtures of water (methanol or ethanol) with an ionic liquid ([BMIM][DMP] or [EMIM][DMP]) at atmospheric pressure in the temperature range of (293.15 to 333.15) K, J. Chem. Eng. Data 57 (2011) 33-39, https:// doi.org/10.1021/je200600p.

[37] H.F.D. Almeida, J.N. Canongia Lopes, L.P.N. Rebelo, J.A.P. Coutinho, M.G. Freire, I.M. Marrucho, Densities and viscosities of mixtures of two ionic liquids containing a common cation, J. Chem. Eng. Data 61 (2016) 2828-2843, https://doi.org/10.1021/acs.jced.6b00178.

[38] Y. Hiraga, M. Goto, Y. Sato, R.L. Smith, Measurement of high pressure densities 
and atmospheric pressure viscosities of alkyl phosphate anion ionic liquids and correlation with the $\varepsilon^{*}$-modified Sanchez-Lacombe equation of state J. Chem. Thermodyn. 104 (2017) 73-81, https://doi.org/10.1016/ j.jct.2016.09.013.

[39] Y. Hiraga, A. Kato, Y. Sato, R.L. Smith, Densities at pressures up to $200 \mathrm{MPa}$ and atmospheric pressure viscosities of ionic liquids 1-Ethyl-3methylimidazolium methylphosphate, 1-Ethyl-3-methylimidazolium diethylphosphate, 1-Butyl-3-methylimidazolium acetate, and 1-Butyl-3methylimidazolium bis(trifluoromethylsulfonyl)imide, J. Chem. Eng. Data 60 (2015) 876-885, https://doi.org/10.1021/je5009679.

[40] C.A. Nieto de Castro, E. Langa, A.L. Morais, M.L.M. Lopes, M.J.V. Lourenço F.J.V. Santos, M.S.C.S. Santos, J.N.C. Lopes, H.I.M. Veiga, M. Macatrão, J.M.S.S. Esperança, C.S. Marques, L.P.N. Rebelo, C.A.M. Afonso, Studies on the density, heat capacity, surface tension and infinite dilution diffusion with the ionic liquids [C4mim][NTf2], [C4mim][dca], [C2mim][EtOSO3] and [Aliquat] [dca], Fluid Phase Equil. 294 (2010) 157-179, https://doi.org/10.1016/ J.FLUID.2010.03.010.

[41] Q. Liu, L. Zhao, Q. Zheng, L. Mou, P. Zhang, Excess molar volume and viscosity deviation of [ $\mathrm{C}_{2}$ mim] [NTf $\left.{ }_{2}\right] /\left[\mathrm{C}_{4} \mathrm{mim}\right]\left[\mathrm{NTf}_{2}\right]+\mathrm{DMC} / \mathrm{DEC}$, J. Chem. Eng. Data 63 (2018) 4484-4496, https://doi.org/10.1021/acs.jced.8b00591.

[42] C. Ye, J.M. Shreeve, Rapid and accurate estimation of densities of roomtemperature ionic liquids and salts, J. Phys. Chem. 111 (2007) 1456-1461, https://doi.org/10.1021/jp066202k.

[43] M.G. Freire, A.R.R. Teles, M.A.A. Rocha, B. Schröder, C.M.S.S. Neves, P.J. Carvalho, D.V. Evtuguin, L.M.N.B.F. Santos, J.A.P. Coutinho, Thermophysical characterization of ionic liquids able to dissolve biomass, J. Chem. Eng. Data 56 (2011) 4813-4822, https://doi.org/10.1021/je200790q.

[44] N.M.C. Talavera-Prieto, A.G.M. Ferreira, P.N. Simões, P.J. Carvalho, S. Mattedi, J.A.P. Coutinho, Thermophysical characterization of N-methyl-2hydroxyethylammonium carboxilate ionic liquids, J. Chem. Thermodyn. 68 (2014) 221-234, https://doi.org/10.1016/j.jct.2013.09.010.

[45] A.R. Mahajan, S.R. Mirgane, Excess molar volumes and viscosities for the binary mixtures of n-octane, n-decane, n-dodecane, and n-tetradecane with octan-2-ol at $298.15 \mathrm{~K}$, J. Thermodyn. 2013 (2013) 1-11, https://doi.org/
$10.1155 / 2013 / 571918$

[46] O. Redlich, A.T. Kister, Algebraic representation of thermodynamic properties and the classification of solutions, Ind. Eng. Chem. 40 (1948) 345-348, https:// doi.org/10.1021/ie50458a036.

[47] M.T. Clough, C.R. Crick, J. Grasvik, P.A. Hunt, H. Niedermeyer, T. Welton, O.P. Whitaker, A physicochemical investigation of ionic liquid mixtures, Chem. Sci. 6 (2015) 1101-1114, https://doi.org/10.1039/C4SC02931C.

[48] J.N. Canongia Lopes, T.C. Cordeiro, J.M.S.S. Esperança, H.J.R. Guedes, S. Huq, L.P.N. Rebelo, K.R. Seddon, Deviations from ideality in mixtures of two ionic liquids containing a common ion, J. Phys. Chem. B 109 (2005) 3519-3525, https://doi.org/10.1021/jp0458699.

[49] H. Niedermeyer, J.P. Hallett, I.J. Villar-Garcia, P.A. Hunt, T. Welton, Mixtures of ionic liquids, Chem. Soc. Rev. 41 (2012) 7780-7802, https://doi.org/10.1039/ c2cs35177c.

[50] G. Annat, M. Forsyth, D.R. MacFarlane, Ionic liquid mixtures-variations in physical properties and their origins in molecular structure, J. Phys. Chem. B 116 (2012) 8251-8258, https://doi.org/10.1021/jp3012602.

[51] N.J. Brooks, F. Castiglione, C.M. Doherty, A. Dolan, A.J. Hill, P.A. Hunt, R.P. Matthews, M. Mauri, A. Mele, R. Simonutti, I.J. Villar-Garcia, C.C. Weber, T. Welton, Linking the structures, free volumes, and properties of ionic liquid mixtures, Chem. Sci. 8 (2017) 6359-6374, https://doi.org/10.1039/ c7sc01407d.

[52] C.M.S.S. Neves, K.A. Kurnia, J.A.P. Coutinho, I.M. Marrucho, J.N.C. Lopes, M.G. Freire, L.P.N. Rebelo, Systematic study of the thermophysical properties of imidazolium-based ionic liquids with cyano-functionalized anions, J. Phys. Chem. B 177 (2013) 10271-10283, https://doi.org/10.1021/jp405913b.

[53] M.A.R. Martins, C.M.S.S. Neves, K.A. Kurnia, P.J. Carvalho, M.A.A. Rocha, L.M.N.B.F. Santos, S.P. Pinho, M.G. Freire, Densities, viscosities and derived thermophysical properties of water-saturated imidazolium-based ionic liquids, Fluid Phase Equil. 407 (2015) 188-196, https://doi.org/10.1016/ j.fluid.2015.05.023.

[54] L. Grunberg, A.H. Nissan, Mixture law for viscosity, Nature 164 (1949) 799-800, https://doi.org/10.1038/164799b0. 